\title{
Aspirin as a neoadjuvant agent during preoperative chemoradiation for rectal cancer
}

\author{
Angelo Restivo*,1, Ivana Maria Francesca Cocco ${ }^{1}$, Giuseppe Casula ${ }^{1}$, Francesco Scintu ${ }^{1}$, Francesco Cabras ${ }^{1}$, \\ Mario Scartozzi ${ }^{2}$ and Luigi Zorcolo ${ }^{1}$ \\ ${ }^{1}$ Department of Surgery, Colorectal Surgery Center, University of Cagliari, Azienda Ospedaliera Universitaria, Policlinico \\ Universitario, Monserrato 09042, Cagliari, Italy and ${ }^{2}$ Department of Medical Sciences, Medical Oncology, University of Cagliari, \\ Azienda Ospedaliera Universitaria, Policlinico Universitario, Monserrato 09042, Cagliari, Italy
}

Background: Recently, many studies have suggested a possible adjuvant role of aspirin in colorectal cancer, reporting a positive prognostic effect with its use in patients with established disease. The aim of this study was to investigate the anticancer effect of aspirin use during preoperative chemoradiation for rectal cancer.

Methods: Two hundred and forty-one patients with stage II-III rectal cancer and candidates for chemoradiation (CRT) were selected and assigned to two groups: group 1, patients taking aspirin at the time of diagnosis, and group 2, all others. Treatment and oncological outcomes were explored.

Results: Aspirin use was associated with a higher rate of tumour downstaging (67.6\% vs $43.6 \%, P=0.01)$, good pathological response $(46 \%$ vs $19 \% ; P<0.001)$, and a slightly, although not significant, higher rate of complete pathological response $(22 \%$ vs $13 \% ; P=0.196)$. Aspirin use was also associated with a better 5 -year progression-free survival $(86.6 \%$ vs $67.1 \%$; hazard rate $(\mathrm{HR})=0.20 ; 95 \% \mathrm{Cl}=0.07-0.60)$ and overall survival $(90.6 \%$ vs $73.2 \% ; \mathrm{HR}=0.21 ; 95 \% \mathrm{Cl}=0.05-0.89)$. Although chance of local relapse was similar $(\mathrm{HR}=0.6 ; 95 \% \mathrm{Cl}=0.06-4.5)$, aspirin use was associated with a lower risk of developing metastasis $(\mathrm{HR}=0.30$; $95 \% \mathrm{Cl}=0.10-0.86)$.

Conclusions: Aspirin might have anticancer activity against rectal cancer during preoperative CRT. This finding could be clinically relevant and should be further investigated with randomised trials.

Preoperative chemoradition (CRT) has been demonstrated to improve the rate of local recurrence in locally advanced rectal cancers and it is now standard of care for these patients (Bosset et al, 2004; Bujko et al, 2006; Gerard et al, 2006).

Although CRT could be considered highly effective in this setting, great differences in treatment response still exist among patients receiving such a treatment approach.

In fact, tumour downstaging can be obtained in approximately half of cases and a complete pathological response is reported to range between 15 and 30\% (Restivo et al, 2013).
Pathological response after CRT has been linked with an improved clinical outcome (Zorcolo et al, 2012). As a consequence, several neoadjuvant trials have been designed and conducted with the aim to enhance response rate, particularly pathological complete response. Unfortunately, the addition of new promising chemotherapeutic drugs and molecular targeted agents to classic regimen with 5-FU and radiotherapy has not been as successful as initially planned (Gerard et al, 2010; Weiss et al, 2010; Aschele et al, 2011). Therefore, the search for new and improved treatment options is still ongoing. 
During the past two decades, a convincing body of evidence from large observational studies as well as randomised clinical trials have reported an inverse link between regular use of aspirin and the risk of developing colorectal adenomas and cancers (Baron et al, 2003; Sandler et al, 2003; Dubé et al, 2007; Flossmann et al, 2007; Logan et al, 2008; Din et al, 2010; Algra and Rothwell, 2012). More recently, many studies have reported a positive prognostic effect with aspirin use in patients with established colorectal cancer (Chan et al, 2009; Bastiaannet et al, 2012; Liao et al, 2012; Walker et al, 2012; Domingo et al, 2013; Ng et al, 2015), thus opening the way to investigate its potential role as an adjuvant therapeutic agent.

Although the underlined mechanism is not well understood yet, these results suggest that aspirin could be effective as a single agent and in synergy with the anticancer activity of 5-FU.

This consideration led us to investigate its effect in patients submitted to preoperative CRT for rectal cancer.

\section{MATERIALS AND METHODS}

From January 2008 to 2014, all consecutive patients diagnosed with histologically confirmed stage II and III rectal tumour at the Colorectal Surgery Center of the University of Cagliari (Italy) who were candidates for preoperative CRT were enrolled in an observational study investigating the role of chronic aspirin use on clinical outcome. Chemoradiation was routinely proposed to every patient with rectal cancer up to $12 \mathrm{~cm}$ from anal verge in pretreatment stage II or III disease.

Patients were assigned to two groups: group 1, including patients who were on aspirin at the start of preoperative CRT, and group 2, including all remaining patients.

Inclusion criteria were as follows:

- histologically proven rectal cancers up to $12 \mathrm{~cm}$ from anal verge and

- pretreatment stage II-III.

Exclusion criteria were as follows:

- not giving or not able to give informed consent,

- pretreatment stage I or IV,

- synchronous colon adenocarcinoma,

- concomitant familial polyposis,

- concomitant inflammatory bowel disease (IBD) and

- other contraindications to preoperative chemotherapy and/or radiotherapy.

All patients signed informed consent to participate in the study. The local Ethical Review Board approved this study.

Tumour downstage was assessed comparing clinical preoperative stage to final pathological stage and was graded as follows:

Downstaged: Any lower T or N stage.

Good pathological response (GPR): Downstaged to pT0-T1 N0 tumours.

Complete pathological response (CPR): Absence of any tumour cells.

Main end point of the study was GPR after treatment. Secondary aims were median progression-free survival (PFS) and overall survival (OS).

Patient's clinical and therapeutic data were collected in a dedicated electronic database. One of the physician conducting the study visited every patient and checked for related data integrity during different established occasions as follows: at the time of diagnosis; after initial workup and before initiating CRT; right after the end of CRT; before surgery; after surgery at the time of hospital discharge and 1 month after; and during every subsequent oncological follow-up visit. In particular, chronic use of aspirin was specifically explored at every visit by collecting details on dosage, date of start and, if the case, temporary or definitive interruptions of treatment.

Preoperative treatment consisted in a long course chemoradiation regimen with a dose of $45 \mathrm{~Gy}$ administered over a 5-week period ( 25 fractions of 1.8 Gy per day) with a three-field technique, followed by a tumour boost of $9 \mathrm{~Gy}$ for a total dose of $54 \mathrm{~Gy}$. Preoperative chemotherapy was based on 5-FU in daily oral preparation (capecitabine $1650 \mathrm{mg} \mathrm{m}^{-2}$ per day) taken during the radiation period.

All patients were included in a follow-up (FU) programme consisting of a flexible rectoscopy every 3 months for the first year, and every 6 months in the second and third year; a complete colonoscopy after the first year, and then after 5 years if negative.

Patients were also monitored with abdominal and chest CT scan every 6 months for the first 3 years, then once yearly until the fifth year; pelvic magnetic resonance imaging (MRI) or endorectal ultrasound every 6 months for 3 years; clinical examination and hematic carcinoembryonic antigen (CEA) dosage every 6 months for the first 3 years, then every year until last follow-up.

The preclinical local stage was assessed by ERUS mostly in combination or sometimes alternatively with pelvic MRI. ERUS procedures were executed all by a single surgeon (Restivo et al, 2015). In cases in which both were implemented, agreement between ERUS and MRI in identifying the tumour to submit to CRT was very high, 95\%. However, when in doubt, ERUS was taken as the gold standard in our patients.

The distance of the tumour from the anal verge and its circumferential position was determined by rigid rectoscopy.

Statistics. The collected variables were analysed for significant differences between the two groups. Categorical variables were analysed with Fisher's exact test with Mid- $p$ correction or $\chi^{2}$ test, whereas continuous variables were tested by Wilcoxon-MannWhitney test. Continuous values are expressed in median with $25-$ 75 percentile.

Survival probability was assessed by Kaplan-Meier estimate. Cox proportional hazard regression models were used for survival and outcomes analysis, adjusting for sex, age $(>$ or $<65$ ), comorbidity (Charlson score $<=2 v s>2$ ), tumour grade and distance from anal verge $(<=5 \mathrm{~cm} v s>5 \mathrm{~cm})$, preoperative stage (II $v s$ III) and surgery (anterior resection/Hartmann $v s$ abdominalperineal resection/proctocolectomy $v s$ local excision). The proportional hazards assumption was satisfied by the Schoenfeld residual method.

All survival analysis were censored at 5 years or last follow-up date, whichever came first: PFS was calculated as the time from enrolment in the study to tumour recurrence or death from any cause; disease-free survival was defined as the time from surgical resection to tumour recurrence or death from any cause; OS was calculated as the time from enrolment to death from any cause. Intent-to-treat analysis was performed using available observations on all participants who entered the study.

Sample size and power. Our hypothesis was that aspirin use during preoperative CRT was associated with a higher rate of pathological response. Based on previous data, the minimum GPR rate for the aspirin group to reject drug efficacy was set to 20\% (Bosset et al, 2005; Gerard et al, 2006). The target number of patients under aspirin use was then set to 33 to detect a $20 \%$ difference with an $\alpha$ of 0.05 and $80 \%$ power (Machin et al, 1997).

\section{RESULTS}

In the period of study, 328 patients were diagnosed with rectal cancer up to $12 \mathrm{~cm}$ from anal verge. Among those, 87 were not 
included because: 12 presented with metastases at initial staging; 64 had a pretreatment stage $<$ II; 2 had a concomitant active IBD; 3 had a synchronous colon adenocarcinoma; and 6 presented with local advanced disease, but preoperative chemotherapy was contraindicated for comorbidities.

Two hundred and forty-one patients, 37 in group 1 (aspirin) and 204 in group 2 (controls), were enrolled in the study from January 2008 to November 2014.

Indication to aspirin treatment was cardiovascular disease prevention in all cases. The daily dose was $100 \mathrm{mg}$ for all patients. Median duration of aspirin therapy before surgery was 5 years $(3-8)$.

Baseline characteristics of the two groups are reported in Table 1. As predictable, considering the indication to aspirin use, patients in this group were older (median age: 71 vs 64 years; $P<0.001)$ and presented with higher comorbidity. The proportion of male patients was slightly higher in the aspirin group $(76.5 \%$ vs $61.9 \%)$, although this difference was not statistically significant $(P=0.101)$.

The two groups were homogeneous for other clinical characteristics. Specifically, variables that have been reported to be associated with pathological response such as tumour distance from anal verge, grading, CEA levels before treatment and platelet count were all comparable in the two groups.

Neoadjuvant treatment outcomes. There was one case of grade IV toxicity, a pulmonary embolism in the Control group $(0.5 \%)$. Grade III toxicity was evident in $4(11 \%)$ and $31(15 \%)$ patients in groups 1 and 2 , respectively $(P=0.514)$. We observed 29 cases of diarrhoea, $4(11 \%)$ in the aspirin group and $23(11 \%)$ in controls, associated or not with grade III proctitis, which was observed in group 2 only (15 cases, $7 \%$ ). Preoperative chemotherapy had to be suspended because of hepatic complication not related to treatment (HCV acute infection) in one patient from group 2; however, the patient continued the entire course of radiotherapy.
In four cases (all in group 2), the entire course had to be suspended because of a myocardial infarction, one intestinal infarction requiring immediate surgery and two cases of severe proctitis with anemia requiring transfusions.

Pathological response and surgical treatment details are reported in Table 2.

Use of aspirin was associated with a higher chance of tumour downstaging. In particular, the main end point of the study, GPR, was significantly higher in the aspirin group (46\% vs 19\%; $P<0.001)$.

Patients in the aspirin group also had a slightly, although not statistically significant, higher rate of CPR (22\% vs $13 \% ; P=0.196)$.

Thirty-three patients (14\%) developed distant metastasis during the preoperative period. Very interestingly, rate of metastasis was significantly lower in patients on aspirin ( $3 \%$ vs $16 \%$; $P=0.036)$.

All patients proceeded to resection of the primary tumour, but in 10 cases (4\%) this consisted in a local excision by transanal endoscopic microsurgery (TEM). Decision was always made after assessment of clinical response. Transanal endoscopic microsurgery was proposed as an alternative to surgery in patients with high surgical risk or refusing radical surgery after CRT.

All other cases were submitted to surgical resection with total mesorectal excision (TME): 157 anterior resections (65\%), 68 abdominal-perineal resections (28\%), 4 Hartmanns (2\%) and 2 proctocolectomies (1\%). Tumour was always resected en bloc, when necessary with part of other organs (e.g. uterus, bladder, bowel tracts). We did not have any case of more extensive surgery as exenteration or sacrectomy.

Recurrences and survival analysis. Median follow-up was 37 (19-57) months. Aspirin was associated with a better PFS $(91.1 \%$ vs $70.4 \%$ at 3 years; $86.6 \%$ vs $67.1 \%$ at 5 years; hazard rate $(\mathrm{HR})=0.20 ; 95 \%$ confidence interval $(\mathrm{CI})=0.07-0.60)$ and $\mathrm{OS}$ ( $97.1 \%$ vs $87.3 \%$ at 3 years; $90.6 \%$ vs $73.2 \%$ at 5 years; $\mathrm{HR}=0.21$; $95 \% \mathrm{CI}=0.05-0.89$ ) (Figure 1 and Table 3 ). This was a likely

Table 1. Baseline characteristics

\begin{tabular}{|c|c|c|c|c|}
\hline Variable & All & Group 1 (aspirin) & Group 2 (controls) & $P$-value \\
\hline & $241(100 \%)$ & $37(15.4 \%)$ & $204(84.6 \%)$ & \\
\hline \multicolumn{5}{|l|}{ Gender } \\
\hline Men & $155(64.3)$ & $29(78.4)$ & $126(61.8)$ & 0.052 \\
\hline Women & 86 (35.7) & $8(21.6)$ & 78 (38.2) & \\
\hline Age (years) & $65(57-72)$ & $71(66-78)$ & $64(56-70)$ & $<0.001$ \\
\hline \multicolumn{5}{|l|}{ ASA score } \\
\hline $1-2$ & $176(73)$ & $16(43.2)$ & $160(78.4)$ & $<0.001$ \\
\hline $3-4$ & $65(27)$ & $21(56.8)$ & $44(21.6)$ & \\
\hline \multicolumn{5}{|l|}{ Charlson score } \\
\hline $1-2$ & 190 & $22(59.5)$ & $168(82.4)$ & 0.004 \\
\hline $3-4$ & 51 & $15(40.5)$ & $36(17.6)$ & \\
\hline \multicolumn{5}{|l|}{ uT } \\
\hline $\begin{array}{l}2 \\
3-4\end{array}$ & $\begin{array}{c}16(6.6) \\
225(93.4)\end{array}$ & $\begin{array}{c}3(8.1) \\
34(91.9)\end{array}$ & $\begin{array}{c}13(6.4) \\
191(93.6)\end{array}$ & 0.696 \\
\hline \multicolumn{5}{|l|}{ uN } \\
\hline+ & $106(44)$ & $13(35.1)$ & $93(45.6)$ & 0.239 \\
\hline- & $135(56)$ & $24(64.9)$ & $111(54.4)$ & \\
\hline \multicolumn{5}{|l|}{ Grading } \\
\hline $1-2$ & $195(80.9)$ & $30(81.1)$ & $165(80.9)$ & 0.977 \\
\hline 3 & $46(19.1)$ & 7 (18.9) & $39(19.1)$ & \\
\hline Distance from anal verge $(\mathrm{cm})$ & $7(5-8)$ & $6(4-8)$ & $7(5-8)$ & 0.505 \\
\hline Tumour size $(\mathrm{cm})$ & $4(4-5)$ & $4(4-5)$ & $4(4-5)$ & 0.736 \\
\hline CEA (ng dl ${ }^{-1}$ ) & $2.4(1.5-6.1)$ & $2.1(1.6-3.2)$ & $2.5(1.5-6.5)$ & 0.205 \\
\hline Platlet count $\left(10^{3}\right)$ & $256(198-314)$ & 224 (191-277) & 261 (209-322) & 0.297 \\
\hline
\end{tabular}


Table 2. Pathological response

\begin{tabular}{|c|c|c|c|c|}
\hline Variable & All & Group 1 (aspirin) & Group 2 (controls) & $P$-value \\
\hline CPR & $34(14.1)$ & $8(21.6)$ & $26(12.7)$ & 0.196 \\
\hline GPR & $56(23.2)$ & $17(45.9)$ & $39(19.1)$ & $<0.001$ \\
\hline Downstaged & $114(47.3)$ & $25(67.6)$ & $89(43.6)$ & 0.011 \\
\hline Pathological stage & & & & 0.019 \\
\hline $\begin{array}{l}0 \\
\text { I } \\
\text { II } \\
\text { III } \\
\text { IV } \\
\text { CRM + } \\
\text { Lymphovascular microscopic invasion } \\
\text { Lymph nodes harvest }\end{array}$ & $\begin{aligned} 40 & (16.6) \\
65 & (27) \\
62 & (25.7) \\
41 & (17) \\
33 & (13.7) \\
5 & (2.2) \\
51 & (21.1) \\
10 & (6-15)\end{aligned}$ & $\begin{aligned} 9 & (24.3) \\
16 & (43.2) \\
6 & (16.2) \\
5 & (13.5) \\
1 & (2.7) \\
1 & (3.1) \\
4 & (10.8) \\
10 & (6-16)\end{aligned}$ & $\begin{aligned} 31 & (15.2) \\
49 & (24.0) \\
56 & (27.5) \\
36 & (17.6) \\
32 & (15.7) \\
4 & (2) \\
47 & (23) \\
9 & (5-15)\end{aligned}$ & $\begin{array}{l}0.529 \\
0.089 \\
0.823\end{array}$ \\
\hline \multicolumn{5}{|l|}{ Surgery } \\
\hline $\begin{array}{l}\text { AR/Hartmann } \\
\text { APR/proctocolectomy } \\
\text { TEM } \\
\text { Interval CRT-surgery (weeks) }\end{array}$ & $\begin{array}{c}161(66.8) \\
70(29) \\
10 \\
10(8-12)\end{array}$ & $\begin{aligned} 21 & (56.8) \\
11 & (29.7) \\
5 & (13.5) \\
10 & (8-11)\end{aligned}$ & $\begin{aligned} 140 & (68.6) \\
59 & (28.9) \\
5 & (2.5) \\
10 & (8-12)\end{aligned}$ & $\begin{array}{l}0.726^{a} \\
0.017^{a} \\
0.348\end{array}$ \\
\hline
\end{tabular}
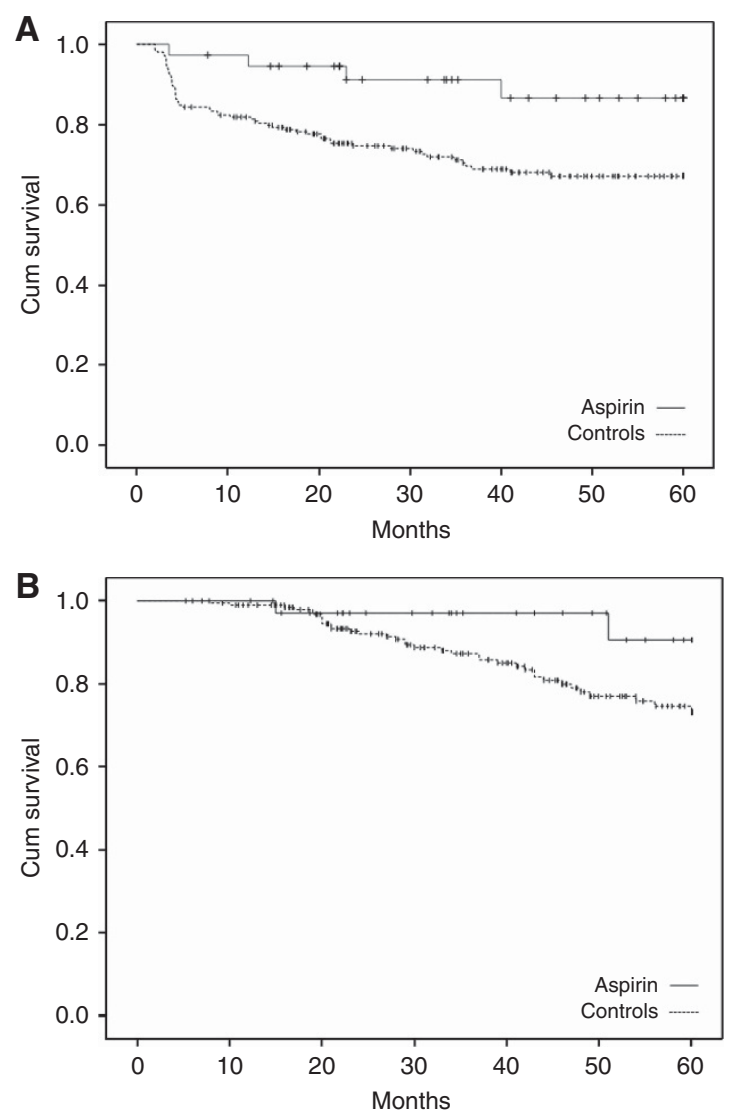

Figure 1. Five year censored Kaplan-Meier curves for: (A) progressionfree survival (PFS), calculated as the time from enrolment in the study to tumour recurrence or death from any cause; and (B) overall survival (OS), calculated as the time from enrolment to death from any cause.

consequence of the lower rate of metastasis in the aspirin group. The overall rate of patients who developed metastatic disease was $23.2 \%$ (56 out of 241 ) in the entire population, $10.8 \%$ (4 out of 37 ) in the aspirin group and $25.5 \%$ (52 out of 204) among controls $(P=0.058 ; \mathrm{HR}=0.30 ; 95 \% \mathrm{CI}=0.10-0.86)$.
Nine patients $(3.7 \%)$ developed local recurrences after surgical resection, $1(2.7 \%)$ patient from the aspirin group and $8(3.9 \%)$ from controls $(P=0.99$; $\mathrm{HR}=0.6 ; 95 \% \mathrm{CI}=0.06-4.5)$.

A subgroup analysis in patients without metastatic disease at the time of surgical resection who underwent a TME with curative intent also showed a slightly better, although not significant, DSF ( $96.7 \%$ vs $83.4 \%$ at 3 years; $87.1 \%$ vs $81.2 \%$ at 5 years; $\mathrm{HR}=0.31$; $95 \% \mathrm{CI}=1.09-1.11)$ and $\mathrm{OS}(100 \%$ vs $93.6 \%$ at 3 years; $90.9 \%$ vs $84.6 \%$ at 5 years; $\mathrm{HR}=0.20 ; 95 \% \mathrm{CI}=0.02-1.67)$ for patients in the aspirin group.

To explore if the association with survival was independent of CRT response, we performed a post hoc analysis adding downstage to the model as an additional covariate. Downstage presented, as predictable, significant better HR for both PFS and OS, 0.27 (95\% $\mathrm{CI}=00.14-0.52)$ and $0.25(95 \% \mathrm{CI}=0.10-0.59)$, respectively. Despite that, aspirin was still associated with a significant better $\mathrm{HR}$ for PFS $(\mathrm{HR}=0.26$; $95 \% \mathrm{CI}=0.09-0.76)$ and with a better but not significant $\mathrm{HR}$ for $\mathrm{OS}(\mathrm{HR}=0.30 ; 95 \% \mathrm{CI}=0.07-1.30)$.

\section{DISCUSSION}

The main finding of this study is that regular aspirin use is associated with a higher rate as well as higher grade of tumour response in patients submitted to neoadjuvant CRT for rectal cancer. The advantage in terms of tumour downstaging seemed clear and clinically relevant. In fact, more than two-thirds of those who were consuming low-dose aspirin during the course of CRT achieved a tumour downstage, leading to cancer regression underneath the submucosae (pT0-T1) in almost $70 \%$ of cases.

A positive effect of aspirin against colorectal cancer was suggested for the first time by Kune et al (1988), who noticed a significant lower rate of aspirin users among new cases of colon and rectal cancer in Melbourne (Australia) metropolitan area (Kune et al, 1988).

Since then, the chemopreventive potential of aspirin has been confirmed by different large cohort studies, in particular through the analysis of data from different large cardiovascular disease prevention trials (Flossmann et al, 2007). Recently, Rothwell et al (2010), in a pooled analysis, have shown that treatment with any aspirin dose between 75-500 mg per day may reduce risk of colon cancer and associated mortality. Moreover, evidences that its 
Table 3. Details of Cox regression analysis for PFS and OS

\begin{tabular}{|c|c|c|c|c|c|}
\hline \multirow[b]{2}{*}{ Covariates } & \multirow[b]{2}{*}{ Reference (1) } & \multicolumn{2}{|c|}{ PFS } & \multicolumn{2}{|c|}{ OS } \\
\hline & & HR & $95 \% \mathrm{Cl}$ & HR & $95 \% \mathrm{Cl}$ \\
\hline Aspirin & No aspirin & 0.2 & $0.07-0.60$ & 0.21 & $0.05-0.89$ \\
\hline Sex & Male & 1.02 & $0.61-1.72$ & 0.93 & $0.46-1.89$ \\
\hline Age & $<65$ & 1.23 & $0.73-2.09$ & 1.11 & $0.56-2.25$ \\
\hline Charlson score & $<3$ & 2.13 & $1.18-3.81$ & 2.13 & $1.03-4.37$ \\
\hline Pretreatment stage & II & 2.09 & $0.50-8.68$ & 1.99 & $0.26-14.9$ \\
\hline Grading & $<3$ & 2.14 & $1.24-3.72$ & 1.54 & $0.76-3.12$ \\
\hline Distance from anal verge $(\mathrm{cm})$ & $<=5$ & 0.78 & $0.37-1.67$ & 0.68 & $0.24-1.90$ \\
\hline \multicolumn{6}{|l|}{ Surgery } \\
\hline APR & AR & 2.05 & $0.94-4.85$ & 1.88 & $0.65-5.47$ \\
\hline TEM & $A R$ & 1.12 & $0.25-4.97$ & 0.88 & $0.10-7.46$ \\
\hline
\end{tabular}

regular use might improve survival on established colorectal cancers are growing, supporting a role of aspirin as an adjuvant agent (Chan et al, 2009; Bastiaannet et al, 2012; Liao et al, 2012; Walker et al, 2012; Domingo et al, 2013; Ng et al, 2015).

Our results suggest that aspirin may also be helpful as a neoadjuvant agent. As this is the first clinical study to report a possible synergic effect with standard preoperative chemoradiation in rectal cancer, no other data are available for direct comparison.

Nevertheless, some in vitro studies have already reported positive anticancer interaction of aspirin with both 5-FU-based chemotherapy and radiation. Ashktorab et al (2005) showed that aspirin potentiates the apoptotic effect of 5-FU on human colon adenocarcinoma cell line (HT-29). They reported that viability of cells treated with a combination of $1.5 \mathrm{~mm}$ aspirin plus 5 -FU for $72 \mathrm{~h}$ was reduced to $48 \%$ compared with $76 \%$ of cells treated with 5-FU alone. Kim et al (2003), in another interesting study, showed that aspirin may inhibit cell growth of human cervical cancer cells by apoptosis while also acting as a radiosensitive factor (Kim et al, 2003). They showed that exposure to $6 \mathrm{~Gy}$ radiation in $1 \mathrm{~mm}$ aspirin-pretreated cells showed a significant increase of $28.7 \%$ in the apoptotic region.

The molecular mechanism by which aspirin could act as an anticancer agent is unclear. The known inhibitory effect of the drug on cyclooxygenase 2 (COX-2; prostaglandin-endoperoxide synthase-2) could explain at least part of its effectiveness, as the related pathway has been shown to be overexpressed in $>80 \%$ of colorectal cancers and in up to $100 \%$ of those with metastatic disease (Eberhart et al, 1994).

Cyclooxygenase 2 overexpression may enhance tumour growth by various mechanisms, including, among others, stem cell stimulation and promotion of angiogenesis and cancer cell survival by inhibition of apoptosis.

In support of a central role of COX-2 inhibition, two large cohort studies recently showed that the survival benefit given by regular aspirin use was limited to patients with colorectal cancers in which COX-2 was overexpressed (Fuchs et al, 2005; Chan et al, 2009).

Other studies, however, have reported variable results by showing differential independent benefits driven by tumour $B R A F$ status and mutations in the gene PIK3CA, which may act as components of the COX-2 pathway(Liao et al, 2012; Domingo et al, 2013; Nishihara et al, 2013), and also by HLA class I antigen expression, which seems independent of the COX-2 pathway (Reimers et al, 2014).

Eventually, aspirin may have more than one target and probably acts in different ways depending on the substrate, dose and duration of therapy. It is well known, for example, that low doses of aspirin (75-300 mg), while producing a partial inhibition of COX-2 in tissue cells, determine a selective irreversible inhibition of COX-1 in platelets (Patrignani et al, 1982).

In our study, long time use of low-dose aspirin has been related to a significant improvement of PFS and OS. This seemed to be influenced mainly by the overall higher rate of distant relapse in the control group $(26 \%$ vs $11 \%)$ and the consequent significant reduced risk of developing metastases in the aspirin group at Cox regression analysis ( $\mathrm{HR}=0.30 ; 95 \%$ $\mathrm{CI}=0.10-0.86$ ). These results are similar to those reported in a recent pooled analysis in which, in colorectal cancer patients without distant disease at initial diagnosis, the HR for later distant relapse was $0.26(95 \% \quad \mathrm{CI}=0.11-0.57 ; \quad P=0 \cdot 0008)$ (Rothwell et al, 2012).

The inhibitory effect of aspirin on platelet activity may explain at least part of its antimetastatic effect. A crucial role of platelets in metastatic progression has been formerly proposed (Gasic et al, 1968). Platelets may favor metastatic dissemination by a sort of 'shield' mechanism, protecting circulating tumour cells from immune system attack (Palumbo et al, 2005), and support subsequent metastasis growth by favouring angiogenesis (Kisucka et al, 2006).

A similar platelet-mediated mechanism could also account for at least part of the effect on tumour response to CRT. Some recent studies, in fact, have reported that thrombocytosis may be a negative predictive factor of response to preoperative chemoradiation in rectal cancer (Kawai et al, 2013; Kim et al, 2015).

In this setting, aspirin may act by increasing the permeability of tumour vessels, thereby rendering them more susceptible to penetration by foreign agents such as chemotherapeutic drug molecules.

Whatever the molecular mechanism is, our data could suggest that aspirin may have acted during neoadjuvant therapy both locally, enhancing the effect of chemoradiation directed to the primary rectal tumour, and systemically, inhibiting the dissemination and/or growth of metastasis. This last effect is very suggestive and seems to be indirectly confirmed by the survival analysis. Despite presenting with higher comorbidity and older age, in fact, patients in the aspirin group still achieved a significant better PFS and OS, suggesting that the effect on distant metastasis and survival could be even greater in the general population.

The main limitation of the study comes from its observational nature. As there was no active indication for its anticancer activity, patients were all taking aspirin before the diagnosis of cancer was made.

It can be questioned that the observed effects on tumour response and survival could actually be secondary to better biologic behaviour given by long time aspirin use before diagnosis rather than on a synergic effect for established cancer. 
Although this possibility cannot be ruled out, it has to be noticed that all the known markers of biologic aggressiveness were comparable between aspirin and controls, making this eventuality unlikely. Another limitation is that, despite different studies having reported an association between various molecular markers and susceptibility to the anticancer effect of aspirin, we did not consider those markers in the multivariate analysis. We decided to include an unselected rectal cancer population, primarily because those gene expression analyses were not part of our routine workup. This limitation, however, could have only led us to underestimate the influence of aspirin in a possible more responsive subgroup.

In summary, this is the first study to propose a role of aspirin as a neoadjuvant therapeutic agent in rectal cancer. Given the observational nature and the relative small sample size, our data should be interpreted cautiously, but we suggest further investigating with a randomised trial the oncological benefit of including aspirin into the CRT regimen.

\section{ACKNOWLEDGEMENTS}

We gratefully acknowledge Sardinia Regional Government for the financial support (POR Sardegna FSE Operational Programme of the Autonomous Region of Sardinia, European Social Fund 20072013 - Axis IV Human Resources, Objective 1.3, Line of Activity 1.3.1 'Avviso di chiamata per il finanziamento di Assegni di Ricerca').

\section{CONFLICT OF INTEREST}

The authors declare no conflict of interest.

\section{REFERENCES}

Algra AM, Rothwell PM (2012) Effects of regular aspirin on long-term cancer incidence and metastasis: a systematic comparison of evidence from observational studies versus randomised trials. Lancet Oncol 13(5): 518-527.

Aschele C, Cionini L, Lonardi S, Pinto C, Cordio S, Rosati G, Artale S, Tagliagambe A, Ambrosini G, Rosetti P, Bonetti A, Negru ME, Tronconi MC, Luppi G, Silvano G, Corsi DC, Bochicchio AM, Chiaulon G, Gallo M, Boni L (2011) Primary tumor response to preoperative chemoradiation with or without oxaliplatin in locally advanced rectal cancer: pathologic results of the STAR-01 Randomized Phase III Trial. J Clin Oncol 29(20): 2773-2780.

Ashktorab H, Dawkins FW, Mohamed R, Larbi D, Smoot DT (2005) Apoptosis induced by aspirin and 5-fluorouracil in human colonic adenocarcinoma cells. Dig Dis Sci 50(6): 1025-1032.

Baron JA, Cole BF, Sandler RS, Haile RW, Ahnen D, Bresalier R, McKeown-Eyssen G, Summers RW, Rothstein R, Burke CA, Snover DC, Church TR, Allen JI, Beach M, Beck GJ, Bond JH, Byers T, Greenberg ER, Mandel JS, Marcon N, Mott LA, Pearson L, Saibil F, van Stolk RU (2003) A randomized trial of aspirin to prevent colorectal adenomas. $N$ Engl J Med 348(10): 891-899.

Bastiaannet E, Sampieri K, Dekkers OM, de Craen AJM, van Herk-Sukel MPP, Lemmens V, van den Broek CBM, Coebergh JW, Herings RMC, van de Velde CJH, Fodde R, Liefers GJ (2012) Use of aspirin postdiagnosis improves survival for colon cancer patients. Br J Cancer 106: 1564-1570.

Bosset JF, Calais G, Daban A, Berger C, Radosevic-Jelic L, Maingon P, Bardet E, Pierart M, Briffaux A, Group ER (2004) Preoperative chemoradiotherapy versus preoperative radiotherapy in rectal cancer patients: assessment of acute toxicity and treatment compliance. Report of the 22921 randomised trial conducted by the EORTC Radiotherapy Group. Eur J Cancer 40(2): 219-224.

Bosset JF, Calais G, Mineur L, Maingon P, Radosevic-Jelic L, Daban A, Bardet E, Beny A, Briffaux A, Collette L (2005) Enhanced tumorocidal effect of chemotherapy with preoperative radiotherapy for rectal cancer: preliminary results - EORTC 22921. J Clin Oncol 23(24): 5620-5627.
Bujko K, Nowacki MP, Nasierowska-Guttmejer A, Michalski W, Bebenek M, Kryj M (2006) Long-term results of a randomized trial comparing preoperative short-course radiotherapy with preoperative conventionally fractionated chemoradiation for rectal cancer. Br J Surg 93(10): 1215-1223.

Chan AT, Ogino S, Fuchs CS (2009) Aspirin use and survival after diagnosis of colorectal cancer. JAMA 302: 649-658.

Din FVN, Theodoratou E, Farrington SM, Tenesa A, Barnetson RA, Cetnarskyj R, Stark L, Porteous ME, Campbell H, Dunlop MG (2010) Effect of aspirin and NSAIDs on risk and survival from colorectal cancer. Gut 59: 1670-1679.

Domingo E, Church DN, Sieber O, Ramamoorthy R, Yanagisawa Y, Johnstone E, Davidson B, Kerr DJ, Tomlinson IP, Midgley R (2013) Evaluation of PIK3CA mutation as a predictor of benefit from nonsteroidal anti-inflammatory drug therapy in colorectal cancer. J Clin Oncol 31(34): 4297-4305.

Dubé C, Rostom A, Lewin G, Tsertsvadze A, Barrowman N, Code C, Sampson M, Moher D (2007) The use of aspirin for primary prevention of colorectal cancer: a systematic review prepared for the U.S. Preventive Services Task Force. Ann Intern Med 146: 365-375.

Eberhart CE, Coffey RJ, Radhika A, Giardiello FM, Ferrenbach S, DuBois RN (1994) Up-regulation of cyclooxygenase 2 gene expression in human colorectal adenomas and adenocarcinomas. Gastroenterology 107(4): 1183-1188.

Flossmann E, Rothwell PM, Trial BDA (2007) Effect of aspirin on long-term risk of colorectal cancer: consistent evidence from randomised and observational studies. Lancet 369(9573): 1603-1613.

Fuchs C, Meyerhardt JA, Heseltine DL, Niedzwiecki D, Hollis D, Chan AT, Saltz LB, Schilsky RL, Mayer RJ (2005) Influence of regular aspirin use on survival for patients with stage III colon cancer: Findings from Intergroup trial CALGB 89803. J Clin Oncol 23(16): 253S-253S.

Gasic GJ, Gasic TB, Stewart CC (1968) Antimetastatic effects associated with platelet reduction. Proc Natl Acad Sci USA 61(1): 46-52.

Gerard J-P, Azria D, Gourgou-Bourgade S, Martel-Laffay I, Hennequin C, Etienne P-L, Vendrely V, Francois E, De La Roche G, Bouche O, Mirabel X, Denis B, Mineur L, Berdah J-F, Mahe MA, Becouarn Y, Dupuis O, Lledo G, Montoto-Grillot C, Conroy T (2010) Comparison of two neoadjuvant chemoradiotherapy regimens for locally advanced rectal cancer: results of the Phase III Trial ACCORD 12/0405-Prodige 2. J Clin Oncol 28(10): 1638-1644.

Gerard JP, Conroy T, Bonnetain F, Bouche O, Chapet O, Closon-Dejardin MT, Untereiner M, Leduc B, Francois E, Maurel J, Seitz JF, Buecher B, Mackiewicz R, Ducreux M, Bedenne L (2006) Preoperative radiotherapy with or without concurrent fluorouracil and leucovorin in T3-4 rectal cancers: results of FFCD 9203. J Clin Oncol 24(28): 4620-4625.

Kawai K, Kitayama J, Tsuno NH, Sunami E, Watanabe T (2013) Thrombocytosis before pre-operative chemoradiotherapy predicts poor response and shorter local recurrence-free survival in rectal cancer. Int J Colorectal Dis 28(4): 527-535.

Kim HJ, Choi GS, Park JS, Park S, Kawai K, Watanabe T (2015) Clinical significance of thrombocytosis before preoperative chemoradiotherapy in rectal cancer: predicting pathologic tumor response and oncologic outcome. Ann Surg Oncol 22(2): 513-519.

Kim KY, Seol JY, Jeon GA, Nam MJ (2003) The combined treatment of aspirin and radiation induces apoptosis by the regulation of bcl-2 and caspase-3 in human cervical cancer cell. Cancer Lett 189(2): 157-166.

Kisucka J, Butterfield CE, Duda DG, Eichenberger SC, Saffaripour S, Ware J, Ruggeri ZM, Jain RK, Folkman J, Wagner DD (2006) Platelets and platelet adhesion support angiogenesis while preventing excessive hemorrhage. Proc Natl Acad Sci USA 103(4): 855-860.

Kune GA, Kune S, Watson LF (1988) Colorectal cancer risk, chronic illnesses, operations, and medications: case control results from the Melbourne Colorectal Cancer Study. Cancer Res 48(15): 4399-4404.

Liao XY, Lochhead P, Nishihara R, Morikawa T, Kuchiba A, Yamauchi M, Imamura Y, Qian ZR, Baba Y, Shima K, Sun RF, Nosho K, Meyerhardt JA, Giovannucci E, Fuchs CS, Chan AT, Ogino S (2012) Aspirin use, tumor PIK3CA mutation, and colorectal-cancer survival. N Engl J Med 367(17): 1596-1606.

Logan RFA, Grainge MJ, Shepherd VC, Armitage NC, Muir KR, Grp uT (2008) Aspirin and folic acid for the prevention of recurrent colorectal adenomas. Gastroenterology 134(1): 29-38.

Machin D, Campbell M, Fayers P, Pinol A (1997) Sample Size Tables for Clinical Studies. 2nd edn. Blackwell Science: Oxford, UK. 
Ng K, Meyerhardt JA, Chan AT, Sato K, Chan JA, Niedzwiecki D, Saltz LB, Mayer RJ, Benson AB, Schaefer PL, Whittom R, Hantel A, Goldberg RM, Venook AP, Ogino S, Giovannucci EL, Fuchs CS (2015) Aspirin and COX-2 inhibitor use in patients with Stage III colon cancer. J Natl Cancer Inst 107(1): 1-5.

Nishihara R, Lochhead P, Kuchiba A, Jung S, Yamauchi M, Liao X, Imamura Y, Qian ZR, Morikawa T, Wang M, Spiegelman D, Cho E, Giovannucci E, Fuchs CS, Chan AT, Ogino S (2013) Aspirin use and risk of colorectal cancer according to BRAF mutation status. JAMA 309(24): 2563-2571.

Palumbo JS, Talmage KE, Massari JV, La Jeunesse CM, Flick MJ, Kombrinck KW, Jirouskova M, Degen JL (2005) Platelets and fibrin(ogen) increase metastatic potential by impeding natural killer cell-mediated elimination of tumor cells. Blood 105(1): 178-185.

Patrignani P, Filabozzi P, Patrono C (1982) Selective cumulative inhibition of platelet thromboxane production by low-dose aspirin in healthy subjects. J Clin Invest 69(6): 1366-1372.

Reimers MS, Bastiaannet E, Langley RE, van Eijk R, van Vlierberghe RLP, Lemmens VEP, van Herk-Sukel MPP, van Wezel T, Fodde R, Kuppen PJK, Morreau H, van de Velde CJH, Liefers GJ (2014) Expression of HLA class I antigen, aspirin use, and survival after a diagnosis of colon cancer. JAMA Intern Med 174(5): 732-739.

Restivo A, Zorcolo L, Cocco IMF, Manunza R, Margiani C, Marongiu L, Casula G (2013) Elevated CEA levels and low distance of the tumor from the anal verge are predictors of incomplete response to chemoradiation in patients with rectal cancer. Ann Surg Oncol 20: 864-871.

Restivo A, Zorcolo L, Marongiu L, Scintu F, Casula G (2015) Limits of endorectal ultrasound in tailoring treatment of patients with rectal cancer. Dig Surg 32: 129-134.
Rothwell PM, Wilson M, Elwin CE, Norrving B, Algra A, Warlow CP, Meade TW (2010) Long-term effect of aspirin on colorectal cancer incidence and mortality: 20-year follow-up of five randomised trials. Lancet 376(9754): 1741-1750.

Rothwell PM, Wilson M, Price JF, Belch JF, Meade TW, Mehta Z (2012) Effect of daily aspirin on risk of cancer metastasis: a study of incident cancers during randomised controlled trials. Lancet 379(9826): 1591-1601.

Sandler RS, Halabi S, Baron JA, Budinger S, Paskett E, Keresztes R, Petrelli N, Pipas JM, Karp DD, Loprinzi CL, Steinbach G, Schilsky R (2003) A randomized trial of aspirin to prevent colorectal adenomas in patients with previous colorectal cancer. N Engl J Med 348(10): 883-890.

Walker AJ, Grainge MJ, Card TR (2012) Aspirin and other non-steroidal anti-inflammatory drug use and colorectal cancer survival: a cohort study. Br J Cancer 107(9): 1602-1607.

Weiss C, Arnold D, Dellas K, Liersch T, Hipp M, Fietkau R, Sauer R, Hinke A, Rodel C (2010) Preoperative radiotherapy of advanced rectal cancer with capecitabine and oxaliplatin with or without cetuximab: a pooled analysis of three prospective phase I-II trials. Int J Radiat Oncol Biol Phys 78(2): $472-478$.

Zorcolo L, Rosman AS, Restivo A, Pisano M, Nigri GR, Fancellu A, Melis M (2012) Complete pathologic response after combined modality treatment for rectal cancer and long-term survival: a meta-analysis. Ann Surg Oncol 19: $2822-2832$.

This work is published under the standard license to publish agreement. After 12 months the work will become freely available and the license terms will switch to a Creative Commons AttributionNonCommercial-Share Alike 4.0 Unported License. 